\title{
Spinal Metastasis of Thymic Carcinoma as a Rare Manifestation: A Summary of 7 Consecutive Cases
}

\author{
Tae Keun Jee, Sun-Ho Lee, Hee Jin Kim, Eun-Sang Kim, Whan Eoh \\ Department of Neurosurgery, Samsung Medical Center, Sungkyunkwan University School of Medicine, Seoul, Korea
}

Backgrounds: Thymic carcinomas are very rare tumors that are often associated with extrathoracic metastasis to other organs. However, it is well known that thymic carcinomas rarely metastasize to the spine, and the prognosis, treatment, and natural course of this disease are not yet standardized.

Methods: We describe seven thymic carcinoma patients with spinal metastasis who were diagnosed and treated in our institute from January 2006 to December 2011. We performed surgical treatment and adjuvant chemotherapy and/or radiation therapy, in consideration of each individual disease's course, and we regularly followed up the patients.

Results: Of the seven patients, five were male and two were female. Six had metastases in the thoracic spine, and one had metastases in the lumbar spine. An extradural lesion was found in five patients, and two patients had both extradural and intradural lesions. The period from the primary diagnosis to spinal metastases varied widely (range, 1.23-14 years). After surgery, all patients showed an improvement of back pain and radicular pain. Two patients were lost to follow-up, but the other five maintained ambulatory function until their final follow-up. Four patients died because of pulmonary complications accompanied with the disease's progression. One patient died from uncontrolled brain metastases. After surgery, the median survival was $204 \pm 111.43$ days.

Conclusion: Because metastasis to the spine from thymic carcinoma is very rare, there are no treatment guidelines. Nevertheless, we suggest that appropriate surgical management of the metastatic lesion is necessary for the preservation of the patient's quality of life during survival.

Key Words: Thymic carcinoma $\cdot$ Spinal metastasis $\cdot$ Surgical management

\section{INTRODUCTION}

Thymic tumors are amongst the most common mediastinal neoplasms. They comprise about $20 \%$ of all mediastinal tumors and up to half of all tumors in the anterior mediastinum in adults and are typically slow-growing tumors that usually metastasize to the pleura, pericardium, or diaphragm, but extrathoracic metastases are unusual ${ }^{2,10)}$. Thymic carcinomas (TC) are invasive, and these rare tumors account for only about 0.06 $\%$ of all thymic neoplasms ${ }^{5}$. However, unlike most thymomas that have indolent features, TC shows overt cytologic features

- Received: June 17, 2014 - Revised: August 1, 2014

- Accepted: August 11, 2014

Corresponding Author: Hee Jin Kim, MD

Department of Neurosurgery, Yangji General Hospital, 1636, Nambusunhwan-ro, Gwanak-gu, Seoul 151-852, Korea

Tel: +82-70-4665-9324, Fax: +82-2-879-1610

E-mail: loveury@hanmail.net

$\otimes$ This is an Open Access article distributed under the terms of the Creative

Commons Attribution Non-Commercial License (http://creativecommons.org/ licenses/by-nc/3.0/) which permits unrestricted non-commercial use, distribution, and reproduction in any medium, provided the original work is properly cited. of malignancy and highly aggressive biological behavior with extrathoracic metastases to the liver, kidney, and bone in 1-15 $\%$ of patients ${ }^{1,8)}$. The differences of metastasis between thymoma and TC have not yet been confirmed precisely ${ }^{2}$.

Despite the highly aggressive behavior of TC, spinal metastasis is rarely reported. As far as we know, this report may be the first case series of the spinal metastasis of TC at a single institution. Survival after treatment and the natural course of the disease are not yet clearly elucidated. We report 7 cases of spinal metastasis in TC patients seen in our clinic and discuss their treatment, results, and survival.

\section{MATERIALS AND METHODS}

\section{Patient Selection}

We retrospectively reviewed the medical records of all patients with spinal metastasis who had surgical removal performed in our institute from January 2006 to December 2011. We reviewed seven cases of TC patients who underwent surgery for spinal metastasis. All metastatic lesions were con- 
firmed pathologically. Relevant clinical data were obtained through a review of the medical records, including operative reports. The records of all the patients were retrieved and the demographic data were collected, including age, gender, the date of the initial diagnosis of the primary site, other metastasis prior to the spinal metastasis, metastatic tumor location, and the symptoms at diagnosis.

All patients were radiographically evaluated using plain radiographs, computed tomography (CT) and magnetic resonance imaging (MRI) of the spine. Bone scintigraphy and/or positron emission tomography CT (PET-CT), as well as the chest and abdomen CT were also perfomed to evaluate systemic metastasis. In addition, the presence of myasthenia gravis (MG) was evaluated. Histologic reviews of TC was performed by two pathologists, according to the proposals of Suster ${ }^{14}$. Every patient had an MRI to diagnose spinal metastasis. The study was independently reviewed and approved by institutional review boards.

\section{Surgical Treatment and Adjuvant Therapy}

Candidates for surgical management were similar to those in previous reports and werecarefully selected, based on the following surgical indications: (1) More than 3-6 months of life expectancy predicted by medical oncologists, (2) presence of indurable severe pain not controlled with analgesics, and (3) presence of a neurologic deficitsuch asweakness ofthe extremities and dysfunction of the bladder/bowel. Each patient had been operated on with appropriate procedures, depending on the surgeon's preference.

The extent of surgical resection, the use of any adjuvant therapy, the length of the follow-up, any evidence of recurrence, and complications were noted. Postoperative complications and their overall survival periods were also evaluated. Adjuvant treatment, either chemotherapy or radiation therapy, was performed in consideration of the individual disease's course. The patients were regularly followedup every month. The length of the follow-up was defined as the period from the date of surgery to the patient's most recent clinic visit. The mean postoperative follow-up period was 207.28 \pm 131.65 days (range: 16-984 days).

\section{Statistical Analyses}

For the investigation of the baseline characteristics of patients, descriptive statistics were used. Student's t-test and Wilcoxon signed rank testwere used for the continuous and parametric values, and the Chi-square test and Fisher's exact test were used for categorical dates andvalues, respectively. Overall survival was estimated using the Kaplan-Meier technique. Statistical analysis was supported by IBM SPSS 21.0 statistical software (IBM Corp., Armonk, NY, USA). A probability value of less than 0.05 was accepted as statistically significant.

\section{RESULTS}

\section{Patient Demographics}

The demographic data of 7 patients are shown in Table 1. Of the 7 patients, five were male and two were female. The mean age of the 7 patients at the time of surgery was 53.86

Table 1. Demographics andelinical and surgical parameters of 7 patients with spinal metastasis of thymic carcinoma

\begin{tabular}{|c|c|c|c|c|c|c|c|c|c|c|}
\hline $\begin{array}{l}\text { Case } \\
\text { No. }\end{array}$ & $\begin{array}{l}\text { Age }(y r) / \\
\text { Sex }\end{array}$ & $\begin{array}{l}\text { Interval } \\
\text { from initial } \\
\text { Dx to meta }\end{array}$ & $\begin{array}{l}\text { Metastatic } \\
\text { spine level }\end{array}$ & Symptoms & $\begin{array}{l}\text { Extrathoracic } \\
\text { metastasis } \\
\text { except spine }\end{array}$ & $\begin{array}{l}\text { Modified } \\
\text { Tokuhashi } \\
\text { score }\end{array}$ & $\begin{array}{l}\text { Tomita } \\
\text { score }\end{array}$ & $\begin{array}{c}\text { Post-operative } \\
\text { complications }\end{array}$ & Status & $\begin{array}{l}\text { Survival after } \\
\text { surgery (days) }\end{array}$ \\
\hline 1 & $61 / M$ & M@P & $\begin{array}{l}\text { Extradural } \\
\text { T4, T5 }\end{array}$ & parapareis & Liver, rib & 11 & 7 & Fluid collection & Died & 986 \\
\hline 2 & $42 / M$ & 2 years & $\begin{array}{l}\text { Extradural } \\
\text { T3, T4, T5 }\end{array}$ & paraplegia & N/A & 9 & 6 & $\begin{array}{l}\text { Recurrent } \\
\text { paraplegia }\end{array}$ & Died & 204 \\
\hline 3 & $36 / M$ & 5 years & $\begin{array}{l}\text { Extradural } \\
\mathrm{T} 2, \mathrm{~T} 3, \mathrm{~T} 4\end{array}$ & paraparesis & $\mathrm{N} / \mathrm{A}$ & 11 & 4 & none & Died & 16 \\
\hline 5 & $68 / M$ & 5 years & $\begin{array}{l}\text { Extra-Intradural } \\
\mathrm{L} 1, \mathrm{~L} 2\end{array}$ & back pain & Brain & 11 & 4 & None & Died & 126 \\
\hline 6 & $57 / M$ & 5 years & $\begin{array}{l}\text { Extradural } \\
\mathrm{T4}, \mathrm{T} 5, \mathrm{~T} 6\end{array}$ & paraplegia & $\begin{array}{l}\text { Adrenal, } \\
\text { Liver }\end{array}$ & 10 & 7 & None & censored & 112 \\
\hline 6 & $59 / \mathrm{F}$ & M@P & Extradural T5 & back pain & N/A & 13 & 4 & None & Died & 226 \\
\hline 7 & $54 / F$ & 14 years & $\begin{array}{l}\text { Extra-Intradural } \\
\text { T11 }\end{array}$ & back pain & Lung, Breast & 12 & 4 & $\begin{array}{l}\text { Transient } \\
\text { voiding difficulty }\end{array}$ & Died & 254 \\
\hline
\end{tabular}

Abbreviations: $M$, male: $F$, female: Dx, diagnosis: $M @ P$, metastasis at presentation: N/A, not applicable 
\pm 4.21 years (range: $36-69$ years). Six patients had metastases in the thoracic spine, including multiple metastases with cord compression, and one patient had metastases in the lumbar spine. Five patients had extradural spinal metastases, and 2 patients had extradural and intradural spinal metastases. The period from the primary diagnosis to spinal metastases varied widely (range: $0-14$ years). On average, it took more than 5 years for metastasis to occur. One patient was diagnosed with metastases to the spine 14 years after being diagnosed with $\mathrm{TC}$ at the primary site. Otherwise, another 2 patients were diagnosed with TC after pathologic confirmation during the surgery for spinal metastases. Four of the 7 patients had metastases in other distant organs, such as the liver, brain, adrenal gland, rib, lung, and breast. Almost every patient had back pain at diagnosis, but 4 patients came with weakness of the lower extremities, and spinal metastases were found in these patients. As it is known that the prognosis of thymoma is related to the co-existence of $\mathrm{MG}$, the presence of $\mathrm{MG}$ was checked, and none of our seven cases had MG.

\section{Surgical Results}

Four of the patients with an epidural metastasis compressing the spinal cord had a posterior-approach decompressive laminectomy and tumor removal following pedicle screw fixation. One patient with vertebral body metastasis and pathologic fractures of the vertebral body without epidural compression underwent pedicle screw fixation to prevent the progression of the pathologic fractures. In two patients with intradural metastasis, extramedullary portion of the tumor were removed. During the surgery, the mean external blood loss was $628.57 \pm$ $655.65 \mathrm{cc}$ (range: $200-2,100 \mathrm{cc}$ ), and the mean operation time was $293.24 \pm 88.00$ minutes (range: $196-420$ minutes). Four patients recovered without complications and their neurological deficits were improved. Transient voiding difficulty was developed in one patient. Fluid collection at the operation site developed in another patient; it was absorbed after conservative care.

There was no postoperative mortality. However, one patient underwent additional surgery for a metastatic tumor that was located in the whole left thoracic cavity two weeks after the spine surgery. After surgery, massive bleeding occurred and the patient expired due to hypovolemic shock.

\section{Follow-up Outcomes}

After surgery, all patients showed improvement of back pain and radiating pain $(\mathrm{p}<0.001$, Wilcoxon signed rank test). Before surgery, five patients had ambulatory function, whether mild neurologic symptoms were apparent. Of the six patients other than the one who expired after further surgery, one patient was lost to follow-up and five patients followed up. All of the five patients maintained ambulatory function until their final follow-up. Four patients died because of pulmonary complications accompanied by the disease's progression. One patient died due to uncontrolled brain metastases, despite whole brain radiotherapy and radiosurgery. The mean overall survival rate after operation was $310.17 \pm 141.81$ days, and the median survival was $226.00 \pm 56.90$ days. The estimated overall survivalgraphusing the Kaplan-Meier techniqueis shown in Fig. 1.

\section{Illustrative Case}

A 54-year-old woman was admitted to our outpatient clinic with flank pain demarcated in the T11 to T12 dermatomes. In her history, she had undergone a thymectomy and had been diagnosed with type B2 thymoma 13 years earlier without adjuvant therapy (T3N0M0). Eleven years after her first diagnosis, the pathologic report of the needle biopsy for recurring mediastinal tumor was changed to TC (WHO grade C). Subsequently, she underwent local radiation therapy with a total dose of $46 \mathrm{~Gy}$, and various chemotherapy cycles according to ACO regimen. Two years after changing the diagnosis to TC, She was referred with segmental thoracic pain in the T11 and T12 dermatomes. She also had lower back pain. A spinal MRI found an enhancing intradural extramedullary mass compressing the spinal cord at the T11 level, and signal change of the T10 to T12 vertebral bodies (Fig. 2A). We performed surgery for the intradural tumor. Postoperatively, her

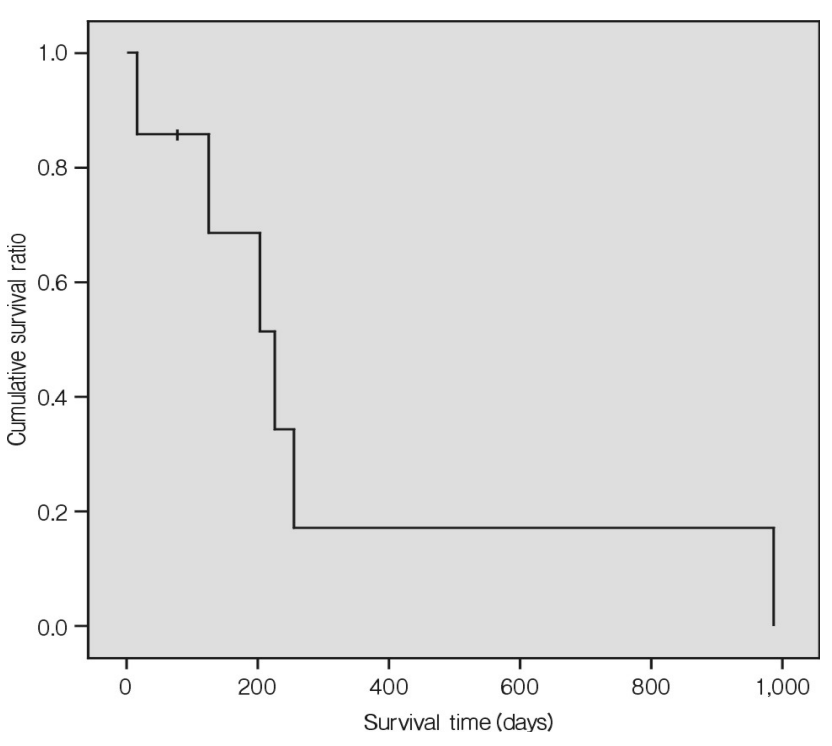

Fig. 1. Estimated overall survival ratio of the 7 patients. The mean overall survival after operation was 310.17 \pm 141.81 days and the median survival was $226.00 \pm 56.90$ days. 

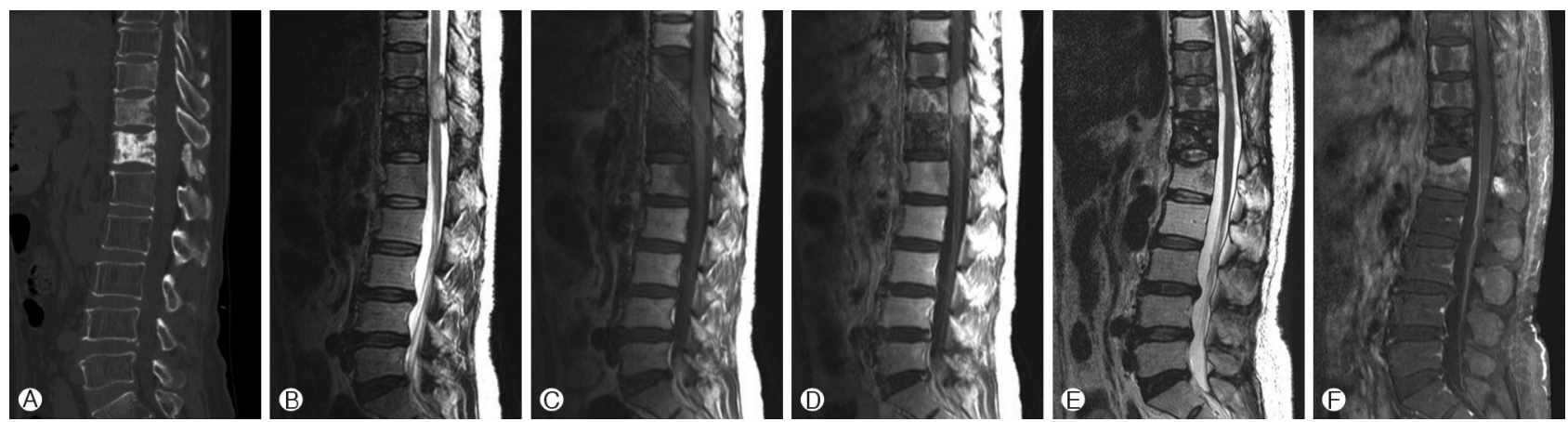

Fig. 2. A 54 year old woman with with flank pain demarcated in the T11 to T12 dermatomes. A: Sagittal non-enhanced computed tomography shows diffusely sclerotic blastic osseous metastasis at the T11 and T12 vertebral bodies. B: T2 weighted, C: pre-contrast T1 weighted and D: Post-contrast T1 weighted magnetic resonance images (MRI) show enhanced mass at the intradural, extramedullary space of T11 level. Six months after surgery, follow up MRI was conducted and E: T2 weighted and F: post-contrast T1 weighted image shows multiple enhancing lesions at the adjacent level of vertebral bodies. But intradural mass was totally removed.

back pain was relieved completely. No complications or neurological deficits were observed. She underwent adjuvant radiotherapy with a total dose of 46 Gy at the T10 and T11 levels. The patient underwent subsequent chemotherapy according to Platino ${ }^{\circledR} /$ Cisplatin, Adriamycin ${ }^{\circledR} /$ Doxorubicin, and Cytoxan ${ }^{\circledR} /$ Cyclophosphamide (PAC) regimen. Six months after the surgery, she had a follow-up spinal MRI and the intradural mass seemed to have been removed successfully, but newly appeared multiple metastases in the vertebral bodies were found (Fig. 2B). Nine months after surgery, she died from respiratory failure due to multiple lung metastases.

\section{DISCUSSION}

Neoplasms in the thymus are differentiated from several following entities including neuroendocrine tumors, germ cell tumors, stromal tumors, tumor-like lesions (such as true thymic hyperplasia), thymic cysts, metastatic tumors, lung cancer, and epithelial origin thymomas ${ }^{11,12)}$. The most widely used staging system for thymoma was developed by Masaoka in 1981, and is based on the degree of tumor encapsulation and the invasion of surrounding structures ${ }^{7}$. According to the World Health Organization (WHO), thymoma is classified into 6 stages depending on its histologic features, which are correlated with the prognosis ${ }^{9}$. Although TC are classified as type $\mathrm{C}$ in $\mathrm{WHO}$ classification, these tumors are not just another variant of thymoma. Their histological features are characterized by a lack of normal thymic differentiation. TC are classified as low-grade tumors (well-differentiated squamous cell, mucoepidermoid, and basaloid carcinoma) or highgrade tumors (poorly differentiated squamous cell, small cell/ neuroendocrine, clear cell, sarcomatoid, and anaplastic/ undifferentiated carcinoma $)^{7,9)}$. Specific immunohistochemical mar- kers and chromosomal gains and losses might be necessary in some cases to distinguish these tumors from other lung carcinomas ${ }^{7}$.

About 15\% of patients with TC have metastases in distant organs, and these metastases favor the liver, kidneys, and bones ${ }^{16}$. However, metastases to the spine or epidural, intradural, or intramedullary space are very rare, and we could find only a few case reports of TC that had metastasized to the spine ${ }^{1,6}$. Vladslav et al. reported 35 cases of the histologically confirmed extrathoracic metastasis of thymomas and TC between the years 1985 and 2011. In this report, there were only three cases of spinal metastasis among the 35 patients ${ }^{4}$.

Generally, in a computed tomographic scan, infiltrated vertebral bodies can show as both osteoblastic and osteolytic lesions $^{3,6}$. MRI features demonstrated extradural lesions with a narrowing of the spinal canal and compression of the dura mater, as well as invasion into the paravertebral muscles. After gadolinium administration, tumors showed strong enhancement. On histological investigation, with regard to the primary findings, spinal metastasis may demonstrate a similar appearance with the presence of polygonal epithelial tumor cells, large vesicular nuclei containing large nucleoli, and many lymphocytes. Although local spreading occurs rapidly, distant spinal metastasis may occur within a long period, up to 14 years after the diagnosis of thymomas. In terms of treatment options, decompression of the spinal cord and complete tumor resection is advised for invasive thymomas. Systemic chemotherapy should be considered in a multimodality protocol if tumor recurrence is expected, and thymomas usually respond well to 45- to 55-Gy radiotherapy.

In our center, we had seven cases of TC that had metastasized to the spine. This might be the first case series of spinal metastasis of TC reported in a single center. In our experience, during four years of a retrograde review, as we mentioned 
in the results, the time interval from the diagnosis of the primary site to metastasis varied. According to our patients, (1) spinal metastatic lesions of TC, similar to most spinal metastases, may result in the destruction of vertebral bodies and spinal instability. (2) However, these tumors may grow into the intradural subarachnoid space with further infiltration of the corresponding nerve roots and compression of the spinal cord. (3) The time intervals from primary diagnosis to spinal metastasis were highly variable in our patient group. Other literature reported that the time interval until metastasis in 35 cases of TC averaged 3.6 years ${ }^{15)}$. (4) In our series, the mean survival period after surgery in six patients was 1.08 years, except for one patient who expired during the early postoperative period. In another report, the five-year survival rate for patients with high-grade TC was $15-20 \%{ }^{13)}$.

From these results, we may speculate that advanced TC with spinal metastasis has a poor prognosis, but surgery can be considered as the treatment of metastatic spinal tumors, to maintain spinal stability and prevent neurological complications. Adjuvant radiation therapy and chemotherapy after surgery may help with local control and improve long-term outcomes.

\section{CONCLUSION}

In our 7 cases and other reports, we found that the character and natural course of metastasis from TC were highly varia ble. It may even manifest with a delay of up to 14 years after diagnosis of the primary tumor. In addition, these tumors may grow with further infiltration of the corresponding nerve roots and compression of the spinal cord.

Although definitive treatment regimens in the spinal metastasis of TC are not yet established, surgical management should be performed for the improvement of neurological status.

\section{REFERENCES}

1. Alafaci C, Salpietro FM, Grasso G, Passalacqua M, Lucerna S,
Romano A, et al: Spinal cord compression by a metastasizing thymoma. Acta Neurochir (Wien) 141:215-216, 1999

2. Falkson CB, Bezjak A, Darling G, Gregg R, Malthaner R, Maziak $\mathrm{DE}$, et al: The management of thymoma: a systematic review and practice guideline. J Thorac Oncol 4:911-919, 2009

3. Giaccone G, Ardizzoni A, Kirkpatrick A, Clerico M, Sahmoud $\mathrm{T}$, van Zandwijk N: Cisplatin and etoposide combination chemotherapy for locally advanced or metastatic thymoma. A phase II study of the European Organization for Research and Treatment of Cancer Lung Cancer Cooperative Group. J Clin Oncol 14:814-820, 1996

4. Giaccone G, Wilmink H, Paul MA, van der Valk P: Systemic treatment of malignant thymoma: a decade experience at a single institution. Am J Clin Oncol 29:336-344, 2006

5. Greene MA, Malias MA: Aggressive multimodality treatment of invasive thymic carcinoma. J Thorac Cardiovasc Surg 125: 434-436, 2003

6. Kondo K, Monden Y: Therapy for thymic epithelial tumors: a clinical study of 1,320 patients from Japan. Ann Thorac Surg 76:878-884; discussion 884-875, 2003

7. Masaoka A, Monden Y, Nakahara K, Tanioka T: Follow-up study of thymomas with special reference to their clinical stages. Cancer 48:2485-2492, 1981

8. Moran CA, Suster S: Thymic carcinoma: current concepts and histologic features. Hematol Oncol Clin North Am 22:393-407, 2008

9. Okumura M, Ohta M, Tateyama H, Nakagawa K, Matsumura A, Maeda H, et al: The World Health Organization histologic classification system reflects the oncologic behavior of thymoma: a clinical study of 273 patients. Cancer 94:624-632, 2002

10. Rajan A, Giaccone G: Treatment of advanced thymoma and thymic carcinoma. Curr Treat Options Oncol 9:277-287, 2008

11. Sobin LH: The international histological classification of tumours. Bull World Health Organ 59:813-819, 1981

12. Strollo DC, Rosado-de-Christenson ML: Tumors of the thymus. J Thorac Imaging 14:152-171, 1999

13. Strollo DC, Rosado-de-Christenson ML, Jett JR: Primary mediastinal tumors: part II. Tumors of the middle and posterior mediastinum. Chest 112:1344-1357, 1997

14. Suster S: Thymic carcinoma: update of current diagnostic criteria and histologic types. Semin Diagn Pathol 22:198-212, 2005

15. Vladislav T, Jain RK, Alvarez R, Mehta RJ, Gokmen-Polar Y, Kesler KA, et al: Extrathoracic metastases of thymic origin: a review of 35 cases. Mod Pathol 25:370-377, 2012

16. Wright CD: Management of thymomas. Crit Rev Oncol Hematol 65:109-120, 2008 